\title{
Cavopulmonary connection after repair of no confluent pulmonary atresia and total anomalous pulmonary venous connection
}

Takashi Miyamoto, MD, Nagata Nobuhiro, MD, Miyaji Kagami, MD, Shinya Kanamoto, MD, and Kitahori Kazuo, MD, Yokohama, Japan

$\mathrm{P}$ atients with single-ventricle physiology in association with asplenia syndrome are common as candidates for the Fontan operation. A combination of nonconfluent pulmonary artery, bilateral patent ductus arteriosus, and total anomalous pulmonary venous connection (TAPVC), however, is rarely identified. We present here a case of heterotaxia in single ventricle in which a fenestrated total cavopulmonary connection (TCPC) was done successfully.

From the Department of Cardiothoracic Surgery, Kanagawa Children's Medical Center, Yokohama, Japan.

Received for publication April 21, 2002; accepted for publication May 16, 2002.

Address for reprints: Takashi Miyamoto MD, Department of Cardiovascular Surgery, Kanagawa Children's Medical Center, 2-138-4 Mutsukawa, Minami-ku, Yokohama, Kanagawa, 232-8555, Japan (E-mail: miyamotot@tk3.speed.co.jp).

J Thorac Cardiovasc Surg 2003;125:731-3

Copyright $\odot 2003$ by The American Association for Thoracic Surgery $0022-5223 / 2003 \$ 30.00+0$

doi: $10.1067 / \mathrm{mtc} .2003 .138$

\section{Clinical Summary}

The patient was a boy aged 4 years, 5 months who had a diagnosis of asplenia syndrome, heterotaxia syndrome, unbalanced atrioventricular canal defect, trivial common atrioventricular valve regurgitation, pulmonary atresia, TAPVC to the left superior vena cava, bilateral superior vena cava, right isomerism, and direct return of the right hepatic vein to the left-sided atrium. Cardiac catheterization revealed satisfactory mean pulmonary artery pressure $(9 \mathrm{~mm} \mathrm{Hg})$, and pulmonary vascular resistance was 1.82 units.

We successively performed a right modified Blalock-Taussig shunt and pulmonary reconstruction for bilateral patent ductus arteriosus and pulmonary atresia at 1 month of age (Figure 1), exchange of right modified Blalock-Taussig shunt at the age of 3 years, 2 months, and a bilateral bidirectional Glenn shunt at 4 years of age. On completion of the bilateral bidirectional Glenn shunt, bilateral central venous pressure increased more than $30 \mathrm{~mm} \mathrm{Hg}$. We performed a pressure study and confirmed pulmonary venous obstruction because there was a significant pressure gradient (13 $\mathrm{mm} \mathrm{Hg}$ ) between the common pulmonary vein and the left-sided atrium. At that time we elected to do a patch augmentation for pulmonary venous obstruction because we wished to leave the

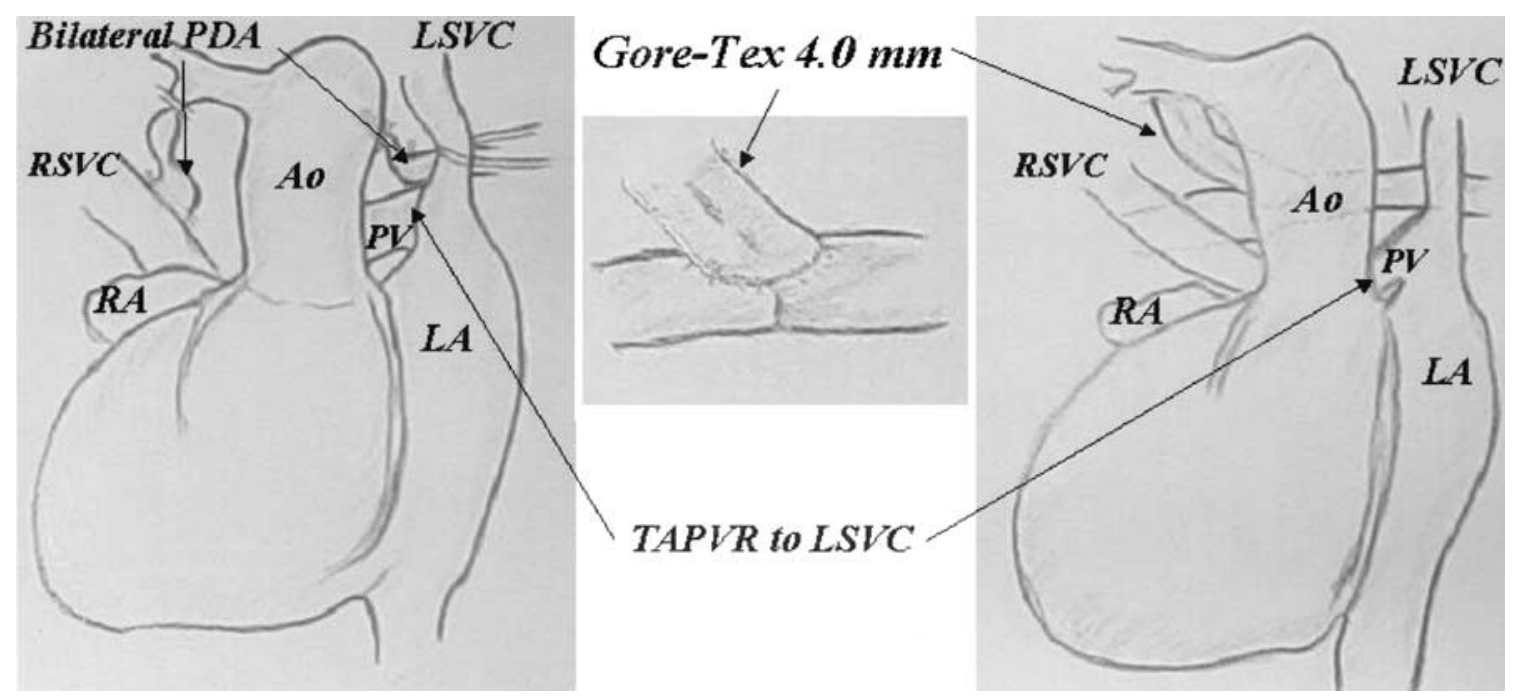

Figure 1. Right modified Blalock-Taussig shunt and pulmonary reconstruction for bilateral patent ductus arteriosus (PDA) and pulmonary atresia. $L S V C$, Left superior vena cava; RSVC, right superior vena cava; $A$, aorta; $P V$, pulmonary vein; $R A$, right atrium; $L A$, left atrium; $T A P V R$, total anomalous pulmonary venous return. Gore-Tex vascular graft, registered trademark of W. L. Gore \& Associates, Inc, Flagstaff, Ariz. 

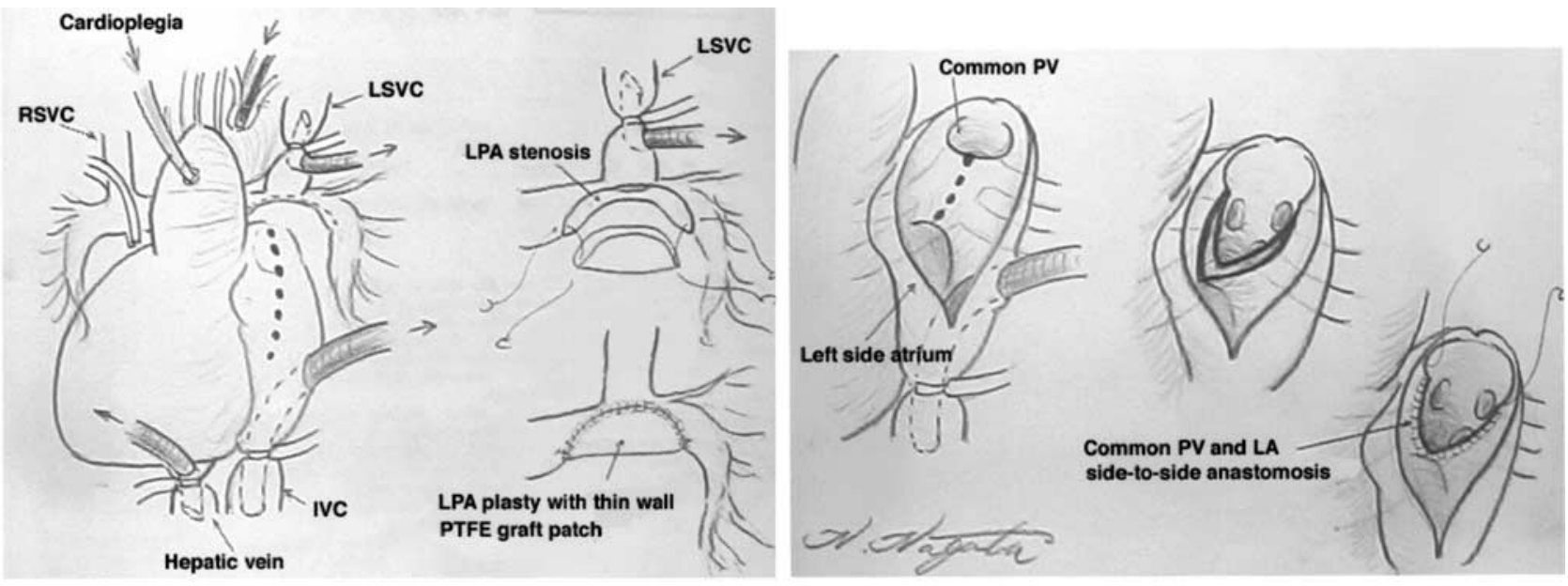

Figure 2. Pulmonary arterioplasty combined with repair of TAPVC. LSVC, Left superior vena cava; RSVC, right superior vena cava; $L P A$, left pulmonary artery; IVC, inferior vena cava; $P T F E$, polytetrafluoroethylene; $P V$, pulmonary vein; $L A$, left atrium.

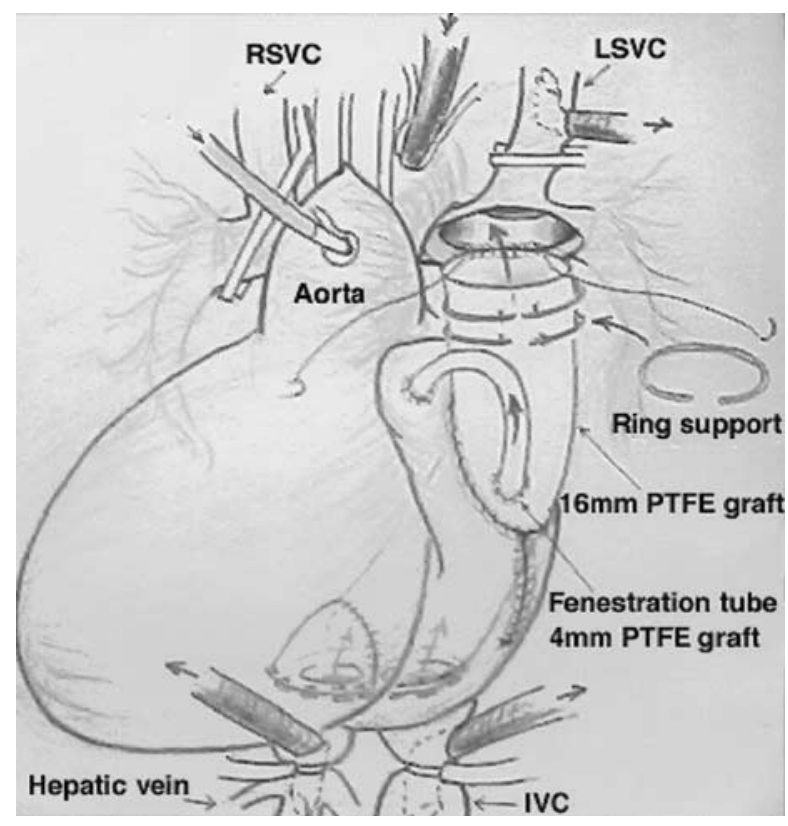

Figure 3. The right atrium was vertically opened. A conduit was connected to the atrial floor around the ostia of the left-sided inferior vena cava (IVC) and suprahepatic venous trunk. The other end of conduit was sewn end to side to the left pulmonary artery. The right atriotomy was closed with the lower half of the conduit located in the atrium and another part in the extracardiac space. A fenestration was created between the extracardiac conduit and pulmonary venous atrium. Finally, two plastic rings were placed in the upper portion of the conduit to prevent potential occlusion by surrounding tissue. RSVC, Right superior vena cava; LSVC, left superior vena cava; PTFE, polytetrafluoroethylene.

door open to further intracardiac TCPC. Subsequently, pulmonary arterioplasty combined with repair of TAPVC was performed at 4 years, 1 month of age (Figure 2).
At 4 years, 2 months of age, the patient underwent a fenestrated TCPC. Before the start of the operation, an extracardiac conduit (16-mm caliber stretched polytetrafluoroethylene vascular graft*) was prepared in a long boot-like structure (bottom wide), appending a 4-mm polytetrafluoroethylene fenestration tube.* With the patient under general anesthesia, the heart was exposed through a resternotomy. Cardiac cannulation was done, and pump perfusion was started. The patient was cooled to $28^{\circ} \mathrm{C}$. After aortic crossclamping, the right atrium was vertically opened. A conduit of a long boot-like graft was connected to the atrial floor around the ostia of left-sided inferior vena cava and suprahepatic venous trunk. The other end of the conduit was sewn end to side to the left pulmonary artery. The right atriotomy was closed with the lower half of the conduit located in the atrium and another part in the extracardiac space. A fenestration was created between the extracardiac conduit and the pulmonary venous atrium. Finally, two plastic rings were placed the upper portion of the conduit to prevent potential occlusion through compression by surrounding tissue. Weaning from cardiopulmonary bypass was achieved without difficulty (Figure 3).

The child was extubated on postoperative day 4 without nitric oxide inhalation therapy and was discharged home on postoperative day 19. He was doing well at the 6-month follow-up.

\section{Comment}

Asplenia syndrome combined with complex single ventricle, which in this case comprised systemic and pulmonary venous connection, pulmonary atresia, and right isomerism patterns, may require specifically planned and timed technical adaptations to obtain an optimal Fontan procedure. ${ }^{1-3}$ We believe that growth and maturation of the pulmonary vascular bed, with the subsequent fall in pulmonary vascular resistance, formed the substrate for successful right heart bypass operations.

*Gore-Tex vascular graft, registered trademark of W. L. Gore \& Associates, Inc, Flagstaff, Ariz. 
Bove and colleagues ${ }^{4}$ reported the case of a patient with heterotaxia and single-ventricle physiology successively undergoing pulmonary arterial banding at 8 months of age, repair of pulmonary vein stenosis at 15 months of age, and a fenestrated TCPC at 5 years of age. Clinically, management of that child's condition was troublesome because of pulmonary and systemic venous hypertension. In light of the grim prognosis of pulmonary vein stenosis in general, however, the case reports a long-term successful outcome of a TCPC after repair of pulmonary vein stenosis. Our patient underwent repair of pulmonary vein stenosis and also repair of nonconfluent pulmonaryartery-supplied bilateral patent ductus arteriosus. We consider our case to be unprecedented.

\section{References}

1. Michielon G, Ghazagozloo F, Julsrud PR, Danielson GK, Puga FL. Modified Fontan operation in the presence of anomalies of systemic and pulmonary venous connection. Circulation. 1993;88:141-8.

2. Heinemann MK, Hanley FL, Van Praagh S, Fenton KN, Jonas RA, Mayer JE, et al. Total anomalous pulmonary venous drainage in newborns with visceral heterotaxy. Ann Thorac Surg. 1994;57:88-91.

3. Gaynor JW, Collins MH, Rychil J, Gaghan JP, Spray TL. Long-term outcome of infants with single ventricle and total anomalous pulmonary venous connection. J Thorac Cardiovasc Surg. 1999;117:506-14.

4. Bove T, Demanet H, Dessy H, Viart P, Deuvaert FE. Cavopulmonary connection after repair of pulmonary vein stenosis. Ann Thorac Surg. 2001;71:725-7.

\section{Primary cardiac ancient schwannoma}

Davinder S. Jassal, MD, FRCPC, ${ }^{a}$ J. F. Légaré, MD, FRCSC, ${ }^{b}$ Brian Cummings, MD, FRCPC, ${ }^{c}$ R. C. Arora, MD, ${ }^{\text {b,d }}$

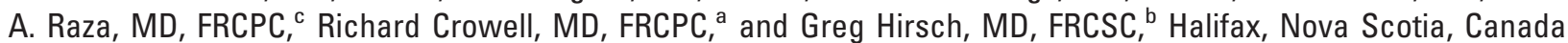

A

49-year-old woman with a history of mitral valve prolapse presented with pleuritic chest discomfort of 2 weeks' duration. During the follow-up period, echocardiography and magnetic resonance imaging (MRI) confirmed a right atrial mass measuring $5 \times 3 \mathrm{~cm}$. After cardiopulmonary bypass, the histologic and immunohistochemical features were consistent with an ancient cardiac schwannoma. To the best of our knowledge, there have been only 5 previous cases of primary cardiac schwannomas described in the literature, all presenting with symptomatic pericardial effusions; our case was notable for its rather benign presentation.

\section{Clinical Summary}

A 49-year-old woman with a history of mitral valve prolapse presented with a 2-week history of episodic pleuritic chest dis-

\footnotetext{
From the Section of Cardiology, Department of Medicine, ${ }^{a}$ the Section of Cardiac Surgery, Department of Surgery, ${ }^{\mathrm{b}}$ the Division of Anatomical Pathology, Department of Pathology and Laboratory Medicine, ${ }^{\mathrm{c}}$ and the Department of Anatomy and Neurobiology, ${ }^{\mathrm{d}}$ Dalhousie University, Halifax, Nova Scotia, Canada.

Received for publication July 12, 1001; accepted for publication July 22, 2002.

Address for reprints: Davinder S. Jassal, MD, FRCPC, Department of Cardiology, Queen Elizabeth II Health Sciences Centre, Room 2134-1796 Summer St, Halifax, Nova Scotia, Canada B3K 6A3 (E-mail: umjassal@hotmail.com).

J Thorac Cardiovasc Surg 2003;125:733-5

Copyright $\odot 2003$ by The American Association for Thoracic Surgery $0022-5223 / 2003 \$ 30.00+0$

doi: $10.1067 / \mathrm{mtc} .2003 .26$
}

comfort. She denied symptoms of exertional dyspnea, orthopnea, palpitations, syncope, or infection or any risk factors for thromboembolism.

The patient was afebrile and normotensive and had no signs of systemic infection. The cardiorespiratory examination was remarkable only for signs of mitral valve prolapse with mild mitral regurgitation. There was no calf or thigh swelling or tenderness.

The complete blood count, electrolyte level, liver function test results, cardiac enzyme level, coagulation parameters, and urinalysis results were within normal limits. Electrocardiography revealed sinus bradycardia with a normal chest radiograph. An echocardiographic examination revealed mild prolapse of the anterior mitral leaflet, mild mitral regurgitation, and a mass measuring $5 \times 3 \mathrm{~cm}$ in size occupying the entire right atrium. Additionally, MRI confirmed a right atrial mass of $5 \times 3 \mathrm{~cm}$ (Figure 1). These diagnostic tests were unable to discern whether the mass was intracavitary or extrinsic in nature. Mammography, bone scan, and infused computed tomography of the abdomen and pelvis were also performed to rule out metastatic malignant disease; results of these studies were normal. A coronary catheterization revealed normal coronary vasculature.

During cardiopulmonary bypass, the mass was identified as originating from the right atrium adjacent to the atrioventricular groove and was successfully removed (Figure 2, A). The specimen consisted of an encapsulated ovoid tumor of $6.4 \times 5.5 \times$ $3.4 \mathrm{~cm}$, with a weight of $70.9 \mathrm{~g}$ and a heterogeneous yellow and white appearance on cut section (Figure 2, B). On microscopy, the tumor consisted of spindled tumor cells with an eosinophilic cytoplasm and elongated nuclei, some demonstrating a wavy appearance (Figure 3,A). Histologic and immunohistochemical features were consistent with an ancient schwannoma (Figure 3, $B)$. 